\title{
Structuring Multidisciplinary Knowledge: Aquatic and Terrestrial Metaphors
}

\author{
Cristina Marras
}

\begin{abstract}
National Resarch Council, ILIESI, Villa Mirafiori - Via Carlo Fea 2, 00161 Rome (Italy), <cristina.marras@iliesi.cnr.it>
\end{abstract}

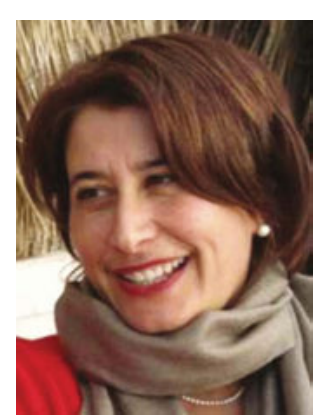

Cristina Marras (Ph.D. in Philosophy, Tel Aviv University) is a researcher at the Italian National Research Council and teaches semiotics at the Department of Philosophy at Sapienza University in Rome. She is a specialist on early modern philosophy and, in particular, on Leibniz studies. She also specializes in the study of scientific and philosophical controversies and in digital humanities (Semantic Web, scientific communities on the Web, open peer review, and research assessment). She has wide experience in managing international interdisciplinary research projects and she is author of several contributions in volumes and journals and of the book Metaphora translata voce.

Marras, Cristina. Structuring Multidisciplinary Knowledge: Aquatic and Terrestrial Metaphors. Knowledge Organization. 40(6), 392-399. 31 references.

\begin{abstract}
In my paper, I will discuss which metaphors appear to be an appropriate conceptual model capable of interpreting and capturing the implicit theoretical and methodological pluralism of knowledge organization. I will propose the use of "aquatic metaphors" for structuring and representing the "new" scenario of knowledge as "open landscape." To this end, I will compare the "aquatic" metaphorical model to the more traditional "terrestrial" one. I will trace back the use of these two metaphorical domains for knowledge organization to the XVII century. A diachronical view will allow us to see how the complexity of the different historical scenarios always requires categories more adequate and capable of describing and interpreting (and organizing) a multilayered knowledge. Multiple approaches and tools for transferring and organizing, as well for distributing and sharing knowledge, are therefore needed. The paper aims at showing how, referring to aquatic metaphors as a model for knowledge organization, we can open the possibility of access to "transversal" points of view, and, in addition to the authoritative knowledge, how they facilitate the creation of entirely new types of interconnections that generates a multi-hierarchical and multidisciplinary knowledge structure.
\end{abstract}

Received and accepted 1 September 2013

\subsection{Introduction: Knowledge and metaphors}

They [the Stoics] compare philosophy to a living being, likening logic to bones and sinews, ethics to fleshier parts, and physics to the soul. They make a further comparison to an egg: Logic is the outside, ethics what comes next, and physics the innermost parts; or, to a fertile field: the surrounding wall corresponds to logic, its fruits to ethics, and its land or trees to physics; or to a city which is well fortified and governed according to reason. (Diogenes Laertius, Lives of Eminent Philosophers VII, 1, 40, translated by Long and Sedley 1987, 158)

The quotation from Diogenes Laertius is just an example of how knowledge and, in particular, different fields of knowledge (philosophy, ethics, logic, and physics) can be organized in different metaphorical domains (body, food, land, tree, and city) and how deeply these domains are, in fact, embedded in our cultural traditions and conceptual schemas. Metaphors are related to different historical and theoretical approaches and to theories about organizing knowledge, which are related to different views of knowledge, cognition, language, and social organization.

A metaphor, given its cognitive and creative resonance, is much more than an episodic linguistic phenomenon. Looking at the use of language, we can see that it requires taking into account a set of contexts wherein the use of a metaphor belongs. In a sense, one might say that, however rich, the lexical resources of a language are insufficient for satisfying the totality of its speakers' expressive needs. The use of semantic means, such as the proliferation of lexemes or their polysemic use barely increases the language's ability to satisfy these needs. Metaphors and other figures of speech become, in this respect, indispensable means to advance in this direction without touching the semantic 
system. Metaphors involve both linguistic expressions and conceptual mappings. Although there is a broad consensus regarding the fact that metaphors lead to changes in and enrichment of knowledge, the mechanism of how this occurs is still under discussion (Gentner and Wolff 2000).

In my paper, I will mainly refer to cognitive theories on metaphors: the theory of conceptual metaphors (Lakoff and Johnson 1980; Lakoff 1993) and the theory of structural mapping (Gentner and Gentner 1983; Gentner 1993). Needless to say that, according to these perspectives, a metaphor is not a mere lexical transfer from a literal domain to a figurative one; on the contrary, it allows concepts, procedures, and tools to be transferred from a known area to a still unexplored area. I will mainly use Fauconnier and Turner's terminology elaborated upon for the conceptual integration network (CIN) or conceptual blending (Fauconnier and Turner 2001). The model consists of a dynamic integration of elements of different input-spaces (instead of the traditional use of source and target). In the CIN, the character of metaphorical concepts emerges through a blending comprising the entire process of interaction between conceptual spaces and their related properties.

I will discuss here terrestrial and aquatic metaphors within the conceptual and theoretical frame sketched above. I chose these two metaphorical domains/spaces for three main reasons: first, because they are the most recurrent scientific knowledge metaphors; second, because, in my opinion, they illustrate the observable change in recent decades in the classification and management of scientific knowledge; and third, they capture, as I will try to show in this paper, the current interdisciplinary scenario strongly influenced by new technologies, helping us to cope and somehow to understand its complexity. I would also like to stress that what I am discussing here is the organization and representation of knowledge more than the process of knowledge acquisition (Hjørland 2008).

Of course, there are other conceptual metaphors used in the domain of knowledge organization, classification, and acquisition; for example, architectural metaphors are used to conceptualize information and knowledge and the organization of libraries (Van Acker and Uyttenhove 2012); or food as a metaphor is one of the most frequently used types of metaphors for knowledge acquisition (Tagliapietra 2005/2006).

As I said above, in this paper, I will discuss the use of terrestrial and aquatic metaphors vis à vis the interdisciplinary scenario we currently are experience. In fact, I would like to point out how these two metaphorical domains work in a complementary manner in the representation and description of a multi and interdisciplinarity approach to knowledge and how they help to overcome the fragmentation of disciplines.
Among all the concepts or key words, such as discipline, interface, and classification, that can help us to understand these interdisciplinary scenarios (Klein 2010), I am mainly focusing on the concept of boundary. Lately, scholars' attention has turned to the different forms of crossfertilization among disciplines, but interdisciplinarity, as well as multi-, trans-, and cross-disciplinarity, seems to be binding together individual disciplinary contributions into single initiatives or topics. The process of integration is basically left to the practices of scholars (i.e., university courses, conferences programs, collective books) and not to a reconceptualization of the epistemology (that is methodology, categories, theoretical frames); a dialectic discussion in order to understand in which way and upon which schemas a dialogue and a fertilization among disciplines can be activated and favored, is actually relatively marginal (Marras 2012).

I will first discuss how spatial metaphors are embedded in the concept of mapping knowledge ( $(1)$; thus I will review some examples of eminent philosophers. In particular, the German philosopher G. W. Leibniz made an original and modern use of aquatic metaphors as conceptual and structuring tools for organizing knowledge (\$2). I will then present the fluidification of disciplinary borders as cause and consequence of the use of new technologies (especially in humanities) and how terrestrial and aquatic metaphors capture this new landscape differently from one another (\$3). Furthermore, I will sketch the shape of the new emerging organization of knowledge ( $\$ 4)$ to propose a conclusion regarding a way to rethink knowledge structures $(\$ 5)$.

\subsection{Spatial metaphors: Mapping knowledge}

The most pervasive knowledge metaphors are spatial metaphors (interesting in this regard is a 2012 issue of $\mathrm{Li}$ brary Trends, "Information and Space: Analogies and Metaphors," edited by Van Acker and Uyttenhove), and the most common approach used to work on knowledge is to map knowledge. Knowledge in fact is usually mapped, and a map is a metaphor and an analytical tool for writing and reading locations and relations between disciplines, concepts, issues, and terms. We map knowledge as we map the Earth. Otlet (1934) was certainly a pioneer for the use of the map in relation to new technologies and their primitive formulations. But the map, spatial instrument par excellence, is not a recent metaphor. D'Alembert (1995, 157; orig. publ. 1751), for example in the "Preliminary speech" to the Encyclopédie said: "and the end of our genealogical distribution (or if you will, our world map) of the science and the arts."

Commonly, disciplines (and related knowledge) are reorganized in terms of boundaries, fences, and bridges. 
Improvements and changes are related to the idea of a tree, usually a growing tree, which needs care. Specific content and topics are presented in terms of buildings, bricks, milestones, nodes, and nets. The process of acquiring knowledge is described in terms of walkways, paths, and roads, requiring a long journey from darkness to light that can either be straightforward or involve "detours."

Mapping is creating visual metaphors for representing information. Geography and cartography are not related to a simple enumerative and descriptive approach, but they allow for the possibility of elaborating upon models of representation in which description and discovery are strictly related. Therefore, it should be stressed that, as maps are redundant due to new discoveries, mapping knowledge requires new ways of sharing maps and identifying places by names.

Mapping implicates and embeds spatial-territorial metaphors in terrestrial and aquatic surfaces. This double presence of these two metaphorical conceptual domains is evident, for example, in the use of the metaphor of navigation and the spatial terminology used to describe activities related to the web. If we look at the language used for describing these landscapes, we note a large use of metaphors of marine terms such as the ocean (the vast amount of information); Navigator, Explorer (tools to navigate the net); pirates (who steal intellectual properties and illegally download copyrighted materials); navigating (accessing sites, searching); surfing (searching the net); fishing, hits (finding data), and many others. These metaphors are used in a complementary way to the use of literary terms such as websites, site maps, IP addresses, visiting sites, following links (terrestrial), along with the persistency of the use of book metaphors like webpages or browsing.

This rich and blended use of metaphors, in my opinion, invites us to rethink the taxonomy and assessment generally used to classify disciplines and sub-disciplines. The dynamic set of nets, threads, maps, and links used in digital domains requires a vocabulary and a language use able to capture integrated and complementary perspectives, static and structural information, and changes over time and space. It is necessary to create innovative environments in which a plural access to individual disciplines and topics can correspond; environments that can enable individuals to create, manage, and preserve information in personalized, idiosyncratic spaces as well.

\subsection{Looking back}

The double metaphorical use of terrestrial and aquatic metaphors, have at least an eminent predecessor in the history of thought: the German philosopher G. W. Leibniz (1646-1716). The centrality of these metaphors is perhaps best explained if we primarily assume the multi-perspecti- val Leibnizian view of the world and knowledge. According to Leibniz, the various individual perspectives (each monad expresses the totality of the universe) require a flexibility of language capable of preserving each perspective's specificity while, at the same time, permitting the harmonization of multiple perspectives. Metaphors are largely used in Leibniz's writings, some of them with a structuring and cognitive role. What is interesting for our purpose is the reseau of metaphors that we can retrace as the interconnection between the Leibnizian uses of the metaphor of the ocean (aquatic) and the metaphor of the way (terrestrial). Both metaphors and their correlated metaphorical domains are used by Leibniz to conceptualize his idea of knowledge and its organization and management, and both are related to the conceptual metaphorical domain of movement (Fernandez 1998; Marras 2010).

On the one hand, the aquatic metaphors play in Leibniz a significant role in conceptualizing the reform of knowledge and disciplinary traditional divisions. In $D e$ l'usage de l'art des combinaisons, Leibniz wrote: "The whole body of science con be viewed as an ocean, which is everywhere continuous, and without any interruption or partition, even though men distinguish it in parts, to which they give names for their own use" (Couturat 1901, 530 33, my translation). On the other hand, the metaphorical use of "way" and related terms articulates the plurality of routes and trajectories appropriate for the different phases, objectives, and participants of the "scientific enterprise" (Leibniz Nowvelles Ouvertures, A VI, 4 A, 691).

The point of view engendered by aquatic metaphors, the vision of an endless, continuous, flat, and fluid aquatic mass, allows for a new vision of the structure of knowledge whose image is no longer that of the usual tree of knowledge. The tree was, is fact, one of the most commonly used metaphors to represent the organization and classification of knowledge. This metaphor belongs to the realm of terrestrial metaphors and traditionally has represented the unity of science and its articulation in different disciplines or branches/fields. The Arbor scientiarum has been interpreted differently: the tree of knowledge of the Old Testament, in Genesis 2, 9; the tree of Porphyry, the Raymond Lull Arbre de sciencia (1482), and Francis Bacon's tree of the Advancement of Learning (1605, II, V, 2):

But because the distributions and partitions of knowledge are not like several lines that meet in one angle, and so touch but in a point, but are like branches of a tree that meet in a stem, which hath a dimension and quantity of entireness and continuance before it come to discontinue and break itself into arms and boughs; therefore it is good, before we enter into the former distribution, to erect and constitute one universal science, by the name of phi- 
losophia prima, primitive or summary philosophy, as the main and common way, before we come where the ways part and divide themselves; which science whether I should report as deficient or no, I stand doubtful.

The tree has been the leading model of knowledge representation and several beautiful tables have been made for describing its inner classification. In the "Table de Mouchon," part of the Table analytique et raisonnée des matières contenues dans les XXXIII volumes in-folio du Dictionnaire des sciences, des arts et des métiers et qui parut en deux volumes, published in Paris in 1780, the Frenchman Pierre Mouchon prepared the analytic index as well as a complete summary of the Encyclopédie of Diderot and D'Alembert including all supplements. In this regard, it is useful to see the dynamic and interactive map of the tree of Diderot and D'Alembert developed in Java by Christophe Tricot that allows one to navigate a complex hierarchical system: http://www.visualcomplexity.com/vc/project.cfm?id=288

What I would like to stress here is this use of the tree as a taxonomy of human knowledge. As Thomas Reid (1764, I) said:

\begin{abstract}
All that we know of nature, or of existences, may be compared to a tree, which hath its root, trunk, and branches. In this tree of knowledge, perception is the root, common understanding is the trunk, and the sciences are the branches.
\end{abstract}

In the XVI and XVII centuries, the building of encyclopedias such as Atlas and the search for a method to order and access all knowledge involved the most prominent scholars (Rossi 2000). Indubitably, Leibniz made a significant and crucial contribution to the secularization of the encyclopedic projects, paving the way for a modern vision of knowledge organization and knowledge policy. His idea and encyclopedia projects do not reflect the perfect order of the Earth and the Universe and are no longer an "imago mundi." The encyclopedia is a tool for the progress of humankind. Leibniz sustained and promoted the advent of academies, public museums, and libraries sponsored by the patrons of scientific research. The German philosopher helped to overcome the idea that research is not a private endeavor that is inaccessible to most people.

For these reasons, the knowledge tree metaphor is not adequate to describe and represent the Leibnizian concept of knowledge plurality as well as the ways to access this plurality. This plurality is, in fact, better described as an ocean (as Leibniz actually did). Rather than the fixed hierarchical classification of sciences implied by the tree metaphor, an ocean-induced vision implies the continuity and cross-fertilization between the disciplines and the flu- idization of their boundaries. Boundaries are depicted through the metaphor of the ocean as more or less arbitrary, like the division of the ocean into seas. They are useful as sign posts, as ways of mapping the ocean of knowledge and providing means of navigating within it, to which, however, no ontological significance should be assigned. Furthermore, like the ocean into which all rivers flow, the contributions to human knowledge come from a variety of sources, ancient and modern, big and small, none of which should be neglected.

The dialogical perspective among disciplines and knowledge domains is strictly connected to Leibniz's encyclopedic project and to his idea of a library's organization. In the concept of encyclopedia, the concept of "paideia" as a complete education is embedded. The emphasis is on the circulation of knowledge: a complete tour around knowledge. An encyclopedia is a map for orientation and a route for an adventurous navigation. Leibniz claimed that an encyclopedia should follow a demonstrative order, yet the order in question varies from preface to preface and from index to index, namely large alphabetic indexes composed according to terms and authors (Leibniz Nouveaux Essais, NE IV, 21, \$1; A VI, 6, 524-527). This variety provides a plurality of ports through which one may access the wealth of information contained in the encyclopedic ocean and crisscross it through different routes (Leibniz NE, IV, 21 \$1; A VI, 6, 523). Nevertheless, the organization and classification of libraries should be reviewed. In fact, there are books that can equally belong to different domains (Leibniz NE, IV, 21, \$1; A VI, 6, 524). The Leibnizian encyclopedia, conceptualized in terms of the ocean rather than the tree metaphor, is an essential tool for the art of discovery. In it lies the capacity to reveal, by its synoptic and comprehensive character, those lacunae-those unknown seas yet to be explored.

The epistemological picture achieved with the ocean becomes in Leibniz more complex once related to the metaphor of the way. The German philosopher elaborated on these two metaphorical domains in extenso. From the issue of the organization of knowledge, the analysis moves toward the theory of knowledge proper. Leibniz emphasized the plurality of ways, i.e., of sources, modes, and kinds of knowledge, and not only the methods for achieving it. Insofar as one can speak of "the" way, it has to be seen as resulting from the complex interconnection of a multiplicity of different ways that, together, constitute the trajectory, which in turn must be viewed in terms of its ensemble of destinations and functions (Leibniz NE IV, 7, §19; A VI, 6, 424). There are infinite ways, Leibniz said, and all of them suppose a surface without borders and limits (Leibniz NE II, 13, §5; A VI, 6, 148). Individual researchers engaged in producing knowledge, which is ultimately destined to contribute to the 
happiness of humankind, must be guided by an ethics of cooperation: knowledge was for Leibniz a joint enterprise.

From Leibniz's use of the knowledge metaphorical reseau, we can borrow at least five important points for our discussion: 1. the concept of open landscape for research and innovation; 2 . mobile/fluid access to sources; 3 . the need for standards vis à vis the preservation of singularities and specificities; 4. the social impact of joint research and the idea of a "scientific community" as a common social and political enterprise; and 5. a challenge in the models of knowledge organization and management.

\subsection{The fluidification of knowledge boundaries}

Among the metaphors that seem to us to be more appropriate in structuring and representing the multiple approaches and tools for transferring and organizing knowledge, aquatic metaphors, in spite of being unsettled and unstable, imply the notion of continuity and interconnection and in particular of the fluidization of the boundaries between disciplines. The composite criteria for identifying needs and opportunities and the presence of multiple paths creates an unexpected relation among (open) tools and practices. As a metaphor that mediates relationships, water is highly mobile, providing a wide range of metaphoric opportunities, but with little apparent central consistency. I turn, briefly, to a list of properties and characterizations that belong to the "sea" of knowledge and generally to aquatic metaphors (Marras 2008 and 2010).

In the sea of knowledge, we can select different properties, such as fluidity, movement, open space, unlimited, borders, unknown parts, the fact that water can be used and navigated in many ways allowing horizontal and vertical movements, travels and explorers, travelling alone or with a crew and ship, and its complex organization. Whereas in the knowledge domain we can select, for instance, properties like organization, open spaces for reorganization, continuity, infinity, openness, exposition to unexpected influences, different ways of organizing knowledge (each reader for example can building her/his own path), diachronic and synchronic research, unlimited research, discoveries, knowledge improvements, educational and cultural aims, not eternal but time-limited and temporary knowledge, cooperation, dialectic knowledge, and collective work.

Scientific knowledge may be organized along many dimensions, from routes to maps with multiple scales or modular models. Aquatic metaphors engender a point of view (fluidity, endless, continuous) that allows for this new vision of the structure of knowledge whose image is no longer that of a landscape with defined borders, frontiers, and structured territory, or the usual tree of knowledge where knowledge is organized in a strict hierarchical way.
Rather than the fixed classifications or structured ways implied by the more traditional metaphors, the aquaticinduced vision emphasizes the circulation of knowledge. Aquatic metaphors thus challenge existing hierarchical understandings of knowledge and promote communication across existing research traditions.

Each part of knowledge is a drop in the universal network of relations with all the other drops, but each drop preserves its own identity. A drop, in fact, does not modify itself when joining other drops; it preserves its internal and external components in spite of a radical modification or even a complete replacement of its parts: water is a part of a river, but no particular drop of water is a part thereof. The continuity of knowledge can be also conceptualized with the boundless propagation of the waves through the fluid medium of water, where everything is in contact with everything else. Waves are in fact an interesting example of how a metaphor is not only a temporary representation of knowledge, but becomes a category of knowledge (Hesse 1966, 11).

The complex interconnection of a multiplicity of different ways together constitute the trajectory, which in turn must be viewed in terms of its ensemble of destinations and functions. We can note that the way and pathway metaphors, strictly related to the terrestrial landscape, are used to guide the access to information related to a specific research field. Implicitly, a pathway indicates a unidirectional motion, whereas the explosion of the amount of information available requires a multidirectional approach or a landscape of possibilities for finding the desired information. The metaphorical process is "multidirectional" rather than "unidirectional." Therefore, the emergence of such a novel territory and its (open and fluid) boundaries shows the interplay of different approaches and tools for knowledge organization and for the hybridization of different disciplines.

\subsection{New emerging knowledge landscapes}

Digital humanities, the former humanities computing discipline (Schreibman et al. 2004) born at the intersections of traditional humanities disciplines and computer science (that is, at the cross point of multi-disciplines), is an example on how cross-border fertilization, namely interdisciplinarity, is possible. Digital humanities opened a scenario requiring innovative and diverse knowledge and its organization. Computational methods and terminology are also being integrated with the traditional ones. No matter the language and the code of a specific discipline, we are currently referring to taxonomies, web ontologies, thesauri, lexical databases, semantic road maps, web archives, and open access, along with the creation of digital infrastructures like digital libraries, archives, repositories, 
and clouds. We are using a blended language and new ways of expression for a new scenario and a new area of research and teaching. Borgman (2003) writes:

Information technologies have the potential to transform the conduct of disciplinary research and to foster new areas of investigation at the boundaries of existing disciplines. Fostering such innovation requires that people have a set of flexible tools and services to gather information from multiple sources, including digital libraries, and to manipulate them for their own purposes.

What is currently discussed is the statute and actual definition of digital humanities (Gold 2012). Scholars have different approaches. The computational humanists apply computational linguistics, count words, and do computational semantics (we can call them the "Father Busa group"); we have scholars who are strictly related to text markup basically following the Text Encoding Initiative Guidelines (TEI) and model (the Vesser group). Thus, we have new communities of scholars belonging to the "spatial humanities" group (i.e., http://spatial.scholarslab.org/ project/). Spatial humanities is a tentative answer to the necessity of mapping the disciplinary cross-border scenario and the overlapping fields that scholars are currently experiencing. There is a large number of visual images available on the web trying to reflect the complexity of the scenario (http://www.visualcomplexity.com). Software has also been developed to explore and represent current knowledge configurations, i.e., the "Knowledge Atlas" (http:/ / www.visualcomplexity.com/vc/project.cfm?id=28 8), a network of maps, diagrams, texts, and peritexts, combined together to describe the space of research in its multifaceted aspects in a sort of "knowledge cartography" (http://www.knowledgecartography.org/). The charting, mining, analyzing, sorting, enabling navigation, and displaying of knowledge are actually ways of mapping knowledge domains. A deep change is occurring in the access to information. Schiffrin and Börner $(2004,5183)$ write:

The changes that are taking place profoundly affect the way we access and use information. Scientists, academics, and librarians have historically worked hard to codify, classify, and organize knowledge, thereby making it useful and accessible. The day is fast approaching when all this knowledge will be coded electronically, but mixed in a vast and largely disorganized and often unreliable sea of mostly recent information. Fishing this sea for desired information is presently no easy task and will continue to increase in difficulty. However, the speed and power of modern computation gives hope that this daunt- ing task can be accomplished. In addition, and perhaps even more important, the new analysis techniques that are being developed to process extremely large databases give promise of revealing implicit knowledge that is presently known only to domain experts, and then only partially.

Knowledge is basically considered a landscape across which science travels. The new digital ways to map, access, and organize scientific knowledge are more correlated to the properties of aquatic metaphors than to the terrestrial ones. Nevertheless, the aquatic and terrestrial metaphorical domains complement each other: beyond these metaphors of knowledge organization and their related metaphorical fields, there is basically the leading idea of fluidity, travel, movement, and journey.

\subsection{Rethinking knowledge structure/s}

Ideas, issues, and texts can be mapped and remapped in a variety of forms, styles, and frameworks. Knowledge is not only a linear and cumulative progression of cognitive techniques, data, information, and theoretical models, but it is rather a critical and dialectical process that uses methodological instruments, conceptual models, behaviors, decisional processes, and operative conducts. Furthermore, knowledge, and more specifically, scientific knowledge, is also the result of continuous, tireless, cooperative work and effort. A flexible and open network of directed and possibly weighted relations allows the coexistence of past, present, and future formal and informal methods and approaches. Individuals and research groups interact in the scientific community thanks to new technologies (e.g., forums, social network, blogs) acting as a complex system of relations and contacts consisting of formal and informal links. Formal and informal contact between scientists, their extended mobility, and their access and (virtual) participation in the scientific community (i.e., tagging, indexing and commenting articles, and sharing notebooks) have led to a new scenario.

Independently of the specific grammar of each scientific field and sub-discipline, the complexity of that scenario described above requires categories and models capable of describing, interpreting, and organizing the many dimensions of scientific knowledge organization. An example of this is the project Zenodo, which, among its other aims, has the goal of "easy access to research results via innovative viewing and as well as open APIs and integration with existing online services and preservation of community independent data formats" (http://www.zeno do.org/about).

If we start to use the aquatic metaphors along with the terrestrial ones, knowledge emerges as a progressive ag- 
gregation of many different atomic parts. In turn, each part is a complex, multilayered object, tightly interconnected to a number of other parts, without a directly identifiable a priori fixed structure.

Wikipedia, and all the "wikis," is one example of the complex multilayered organization of knowledge combined with the complexity of multidisciplinary, apparent unorganized, scientific contributions. These aspects render this Wikipedia certainly an interesting case study for collaborative web-based encyclopedias as complex networks. Moreover, the emerging possibility of accessing "transversal" points of view, in the spirit of Leibniz's view, in addition to authoritative knowledge, facilitates the generation of entirely new types of interconnections that generate a multi-hierarchical knowledge structure.

This process of knowledge organization, which most recently has been described as the emergence of a new landscape, requires a growing ability to access and organize complex information (examples include collaborative websites, content management systems, online reference management services, and folksonomy tagging). It is evident that this organization of knowledge possesses far less structure than one might expect. Such a fact implies a paradigm shift that forces a shift from the dichotomic interplay between bottom-up and top-down approaches to a middle-out model of knowledge. This apparent lack of structure seems to create a gap between practices and theories of knowledge, or between the set of principles and practices that promote access to texts and to the environments implicated in cognition distribution. Alternatively, the apparent lack of structure on the one hand allows informal and equalitarian access to knowledge sources and, on the other hand, represents, under appropriate prerequisites, an opportunity to bridge the gap between theory and practice. A deep (cultural) change is still needed in the approach to the theoretical frame and the practice of scholarly research in communicating ideas and sharing practices and results (Ciula 2013). Innovative work on scientific corpus is needed where corpus here is intended in a wider sense, including nontraditional modalities as well to organize and communicate contents (such as E-books, webcasts, and podcasts).

Digital humanities, as described in section 5 , has grown over the past three or four years, sweeping across a number of academic fields and sub-fields. This is just one example of how the potential of new tools should be exploited to overcome traditional boundaries between disciplines, and at the same time, accepting the value of unforeseen modalities of aggregating, cataloguing, and exploring texts (Moulin et al. 2011). However, a significant amount of work still needs be done in this area. The aquatic and terrestrial metaphors, in terms of their cognitive and structural power, can help us to rethink the disciplinary borders and reshape the terms of a debate about the nature of scholarly research, evaluation, and publication related to new knowledge organization, access, and policy.

\section{References}

Bacon, Francis. 1605. Advancement of learning. Available http://www.gutenberg.org/ebooks/5500.

Borgman, Christine L. 2003. Personal digital libraries: creating individual spaces for innovation. Presented at NSF Workshop on Post-Digital Libraries Initiative Directions. Chatham, MA 4 June 2003. Available http://www.sis. pitt.edu/ dlwkshop/paper_borgman.pdf.

Ciula, Arianna. 2013. Which changes are currently taking place in our research and academic culture? Presented at the Research conditions and digital humanities. What are the prospects for the next generation?, DHIP IHA, Paris 11 June 2013. Available http://de.slideshare.net/arimare/ presentation-ciulaparis 2013

Couturat, Louis. 1901. La logique de Leibniz: d'après des documents inédits. Paris: F. Alcan.

D’Alembert, Jean Le Rond. 1995. Preliminary discourse to the Encyclopedia of Diderot. Chicago, IL: University of Chicago Press.

Fauconnier, Gilles and Turner, Mark. 2001. Conceptual integration network. Available http://www.cogsci.ucsd.edu/ $\sim$ faucon/BEIJING/CIN.pdf

Fernandez, Francisco, J. 1998. El filósofo del océano. Irun: Iralka.

Gentner, Dedre. 1993. From metaphor to analogy in science. In Ortony, Andrew, ed. Metaphor and thought (2nd ed.). New York: Cambridge University Press, pp. 447-80.

Gentner, Dedre and Gentner, Donald R. 1983. Flowing waters or teeming crowds: mental models of electricity. In Gentner, Dedre and Stevens, Albert, eds., Mental models. Hillsdale, NJ: Lawrence Erlbaum Associates Publishers, pp. 99-129.

Gentner, Dedre and Wolff, Phillip. 2000. Metaphor and knowledge change. In Dietrich, Eric and Markman, Arthur B., eds., Cognitive dynamics: conceptual change in buman and machines. Mahwah, NJ: Lawrence Erlbaum Associates, pp. 295-342.

Gold, Mathieu. 2012. Debates in digital bumanities. Minneapolis, MN: University of Minnesota Press.

Hesse, Mary. 1966. Models and analogies in science. Notre Dame, IN: University of Notre Dame Press.

Hjørland, Birger. 2008. What is knowledge organization (KO)? Knowledge organization 35: 86-101.

Klein, Julie Thompson. 2010. The metaphorics of mapping interdisciplinary knowledge. In The future of knowledge. Mapping interfaces. Interdisciplinary workshop report, Reykjavik, 16-17 June 2009. Strasbourg: European Science Foundation, pp.18-24. 
Lakoff, Georg. 1993. The contemporary theory of metaphor. In Ortony, Andrew, ed., Metaphor and thought (2nd ed.). New York: Cambridge University Press, pp. 202-51.

Lakoff, Georg and Johnson, Marc. 1980. Metaphors we live by. Chicago, IL: University of Chicago Press.

Leibniz, Gottfried Wilhelm. 1686. Nouvelles ouvertures. In Schepers, Heinrich, Schneider, Martin and Biller, Gerhard, eds., Sämtliche Schriften und Briefe, ser. 6: Philosophische Schriften, vol. 4-A (A VI, 4 A), 1999. Berlin: Akademie Verlag, pp. 686-91.

Leibniz, Gottfried Wilhelm, 1765. Nouveaux essais sur l'entendement humain. In Robinet, André and Schepers, Heinrich, eds., Sämtliche Schriften und Briefe, ser. 6: Philosophische Schriften, vol. 6 (A VI, 6), 1962. Berlin: Akademie Verlag.

Long, Anthony A. and Sedley, David, N. 1987. The Hellenistic philosophers, vol. 1: translation of the principal sources, with philosophical commentaries. Cambridge, UK: Cambridge University Press.

Marras, Cristina. 2008. The role of metaphor in Leibniz's epistemology. In Dascal, Marcelo, ed., Leibniz: what kind of rationalist? Dordrecht: Springer Academics Publisher, pp. 199-212.

Marras, Cristina. 2010. Metaphora translata voce. Prospettive metaforiche nella filosofia di Leibniz. Florence: Olschky.

Marras, Cristina. 2012. Pragmatica e comunicazione: orizzonti interdisciplinari. In Gensini, Stefano and Forgione Luca, eds., Filosofia della comunicazione. Rome: Carocci, pp. 253-78.

Mouchon, Pierre. 1780. Table analytique et raisonnée des matières contenues dans les XXXIII volumes in-folio du dictionnaire des sciences, des arts et des métiers et qui parut en deux volumes. Paris: Panckoucke.
Moulin, Claudine, Nyhan, Julianne, Ciula, Arianna Ciula, Kelleher, Margaret, Mittler, Elmar, Tadić, Marko, Ågren, Maria, Bozzi, Andrea, and Kuutma, Kristin.2011. Research infrastructures in the digital humanities. ESF 42 Science Policy Briefing, September 2011. Available http://www.esf. org/fileadmin/Public_documents/Publications/spb42_ RI_DigitalHumanities.pdf.

Otlet, Paul. 1934. Traité de documentation: le livre sur le livre. Théorie et pratique. Bruxelles: Editiones Mundaneum.

Reid, Thomas. 1764. An inquire into the buman mind on the principles of common sense. London: T. Cadell in the Strand.

Rossi, Paolo. 2000. Logic and the art of memory: the quest for a universal language. London: Athlone Press.

Shiffrin, Richard M. and Boerner, Katy. 2004. Mapping knowledge domain. Proceedings of the National Academy of Sciences 101(suppl. 1): 5186-91. Available http://www. ncbi.nlm.nih.gov/pmc/articles/PMC387293/pdf/1015 183.pdf.

Schreibman, Susan, Siemens, Ray and Unsworh, John. 2004. A companion to digital humanities. Oxford: Blackwell. Available http://www.digitalhumanities.org/ companion.

Tagliapietra, Andrea. 2005/2006. La gola del filosofo. Il mangiare come metafora del pensare. XÁOS. Giornale di confine IVn1. Available http://www.giornalediconfine. net/n_4/1.htm

Van Acker, Wouten and Uyttenhove, Pieter. 2012. Analogous spaces: an introduction to spatial metaphors for the organization of knowledge. Library trends 61: 25970 . 